\section{Interleukin 22, a Potential Therapeutic Target for Rheumatoid Arthritis}

To the Editor:

A recent report by Da Rocha, et al indicated that levels of interleukin 22 (IL-22) were increased in patients with rheumatoid arthritis (RA) compared with controls; levels of IL-22 correlated with Disease Activity Score (DAS28) and Clinical Disease Activity Index measures, rheumatoid factor positivity was correlated with higher levels of IL-22 in patients with RA, and the presence of bone erosions was associated with high IL-22 levels ${ }^{1}$. These findings suggest that IL-22 may be a good biomarker for assessment of activity in RA, and IL-22 seems to be a potential therapeutic target for RA.

Other studies have indicated the similar relationship between IL-22 and RA, where serum IL-22 levels were found to be increased in patients with RA compared with controls $2,3,4,5$, and high IL-22 levels correlated with bone erosions ${ }^{4}$. The IL-22 concentration in synovial fluid was higher in patients with RA compared with controls ${ }^{2,3}$. In patients with RA, Th17 cells were recognized to produce higher IL-22 ${ }^{4}$. Th22 cells also produced IL-22 and the expression of Th22 cells. IL-22 were significantly elevated in RA patients ${ }^{5,6}$. More importantly, Th17/22 cells showed positive correlations with IL-22, C-reactive protein, and DAS28 data ${ }^{6}$. In addition, natural killer (NK)-22 cells in vitro can secrete higher levels of IL-22 and tumor necrosis factor- $\alpha$ (TNF- $\alpha$ ), and NK-22 supernatant can induce the proliferation of RA fibroblast-like synoviocytes (FLS); however, addition of IL-22 antibody plus TNF- $\alpha$ antibody inhibited the proliferation of FLS induced by the NK-22 supernatant ${ }^{7}$. In vitro, human recombinant IL-22 (rhIL-22) significantly increased proliferation of RA synovial fluid and FLS and production of monocyte chemoattractant protein- $1^{3,7,8}$, but an inhibitory effect of anti-IL-22R antibody on proliferation of FLS induced by rhIL-22 was found in $\mathrm{RA}^{3}$. Moreover, an experimental arthritis model (IL-1Ra-/-) displayed a progressive erosive arthritis characterized by upregulation of IL-22 in severely inflamed synovia; and anti-IL-22 treatment of IL-1Ra-/mice significantly reduced the inflammation and bone erosions ${ }^{9}$. Similarly, in studies of collagen-induced arthritis (CIA), serum IL-22 levels were increased, and the specific IL-22RI was expressed in lymphoid tissue, including splenocytes. IL-22-/- mice were less susceptible to CIA than wild-type mice, as shown by their reduced incidence of arthritis and decreased pannus formation. Remarkably, the less severe form of arthritis in IL-22-/- mice was associated with increased production of collagen II-specific and total IgG antibodies. In vitro, IL-22 was found to promote osteoclastogenesis, a process that may contribute to its proinflammatory activity in $\mathrm{CIA}^{10}$. On the other hand, 1,25-dihydroxyvitamin D3 $(1,25[\mathrm{OH}] 2 \mathrm{D} 3)$ prevented corticosteroid-induced osteoporosis in patients with early RA, where $1,25[\mathrm{OH}] 2 \mathrm{D} 3$ directly modulated human Th17 polarization, accompanied by suppression of IL-17, TNF- $\alpha$, and IL-22 production $^{11}$. In patients with RA, rituximab reduced expression of IL-22 and Th17-positive cells in synovial tissue, and this correlated with better clinical outcomes. In vitro, rituximab strongly reduced IL-17 and IL-22 production induced by Candida albicans ${ }^{12}$.

These findings suggest therapeutic potential for patients with RA, and suggest a role for IL-22 in development of RA. Further studies are needed to clarify the role of IL-22 in RA. Therapeutic agents targeting IL-22 might result in innovative new therapies for RA.
QIANG XIE, MD, School of Pharmacy, Anhui Medical University, PET/CT Center, Anhui Provincial Hospital; SHI-CUN WANG, MM PET/CT Center, Anhui Provincial Hospital; JUN LI, MD, School of Pharmacy, Anhui Medical University, 81 Meishan Road, Hefei, Anhui, 230032, PR China. Address correspondence to Dr. Li;

E-mail: lijun@ahmu.edu.cn

\section{REFERENCES}

1. Da Rocha LF Jr, Duarte AL, Dantas AT, Mariz HA, Pitta ID, Galdino SL, et al. Increased serum interleukin 22 in patients with rheumatoid arthritis and correlation with disease activity. J Rheumatol 2012;39:1320-5.

2. Kim KW, Kim HR, Park JY, Park JS, Oh HJ, Woo YJ, et al. Interleukin-22 promotes osteoclastogenesis in rheumatoid arthritis through induction of RANKL in human synovial fibroblasts. Arthritis Rheum 2012;64:1015-23.

3. Mitra A, Raychaudhuri SK, Raychaudhuri SP. Functional role of IL-22 in psoriatic arthritis. Arthritis Res Ther 2012;14:R65.

4. Leipe J, Schramm MA, Grunke M, Baeuerle M, Dechant C, Nigg AP, et al. Interleukin 22 serum levels are associated with radiographic progression in rheumatoid arthritis. Ann Rheum Dis 2011;70:1453-7.

5. Zhang L, Li JM, Liu XM, Ma DX, Hu NW, Li YG, et al. Elevated Th22 cells correlated with Th17 cells in patients with rheumatoid arthritis. J Clin Immunol 2011;31:606-14.

6. Zhang L, Li YG, Li YH, Qi L, Liu XG, Yuan CZ, et al. Increased frequencies of Th22 cells as well as Th17 cells in the peripheral blood of patients with ankylosing spondylitis and rheumatoid arthritis. PloS One 2012; 7:e31000.

7. Ren J, Feng Z, Lv Z, Chen X, Li J. Natural killer-22 cells in the synovial fluid of patients with rheumatoid arthritis are an innate source of interleukin 22 and tumor necrosis factor- $\alpha$. J Rheumatol 2011;38:2112-8.

8. Ikeuchi H, Kuroiwa T, Hiramatsu N, Kaneko Y, Hiromura K, Ueki $\mathrm{K}$, et al. Expression of interleukin-22 in rheumatoid arthritis: Potential role as a proinflammatory cytokine. Arthritis Rheum 2005;52:1037-46

9. Marijnissen RJ, Koenders MI, Smeets RL, Stappers MH, Nickerson-Nutter C, Joostern LA, et al. Increased expression of interleukin- 22 by synovial Th17 cells during late stages of murine experimental arthritis is controlled by interleukin-1 and enhances bone degradation. Arthritis Rheum 2011;63:2939-48.

10. Geboes L, Dumoutier L, Kelchtermans H, Schurgers E, Mitera T, Renauld JC, et al. Proinflammatory role of the Th17 cytokine interleukin-22 in collagen-induced arthritis in C57BL/6 Mice. Arthritis Rheum 2009;60:390-5.

11. Colin EM, Asmawidjaja PS, van Hamburg IP, Mus AM, van Driel M, Hazes JM, et al. 1,25-Dihydroxyvitamin D3 modulates Th17 polarization and interleukin-22 expression by memory $\mathrm{T}$ cells from patients with early rheumatoid arthritis. Arthritis Rheum 2010;62:132-42.

12. van de Veerdonk FL, Lauwerys B, Marijnissen RJ, Timmermans K, Di Padova F, Koenders MI, et al. The anti-CD20 antibody rituximab reduces the Th17 cell response. Arthritis Rheum 2011;63:1507-16.

J Rheumatol 2012;39:11; doi:10.3899/jrheum.120757 